\title{
Interleukin-15 and Interleukin-15 Receptor $\alpha$ mRNA-engineered Dendritic Cells as Promising Candidates for Dendritic Cell-based Vaccination in Cancer Immunotherapy
}

\author{
Johan MJ Van den Bergh" ${ }^{1 *}$, Eva Lion', Sebastien Anguille ${ }^{1}$, Van Tendeloo FI ${ }^{1}$ and Evelien LJM Smits ${ }^{1,2}$ \\ ${ }^{1}$ Faculty of Medicine and Health Sciences, Vaccine and Infectious Disease Institute, University of Antwerp, Antwerp, Belgium \\ ${ }^{2}$ Faculty of Medicine and Health Sciences, Center for Oncological Research, University of Antwerp, Antwerp, Belgium
}

\begin{abstract}
Dendritic cell (DC)-based tumor vaccination holds great potential and is intensively being studied in cancer immunotherapy. Although DC vaccination can result in a survival advantage as shown in various cancer types, there is still room for improvement. Therefore, current DC vaccines urge rigorous optimization in order to increase their immune stimulating capacities for induction of antitumor immunity. In this context, strategies where the interleukin (IL)-15 transpresentation mechanism is incorporated, appear to be of great value due to the activating potential of IL-15 towards IL-15Rßy-expressing cells, such as cytotoxic T lymphocytes (CTLs) and natural killer (NK) cells. In the past 5 years, our research group designed different strategies to generate IL-15-expressing DC with superior T cell and NK cell-activating properties. In this review, we briefly describe the design of our latest DC vaccine, in which DC are genetically engineered to transpresent IL-15 via mRNA electroporation and discuss the capacity of this newly designed DC vaccine to activate NK cells and CTLs. Overall, IL-15-transpresenting DC show the potential to activate antitumor immunity and are promising candidates for DC-based cancer immunotherapy.
\end{abstract}

Keywords: Interleukin-15; IL-15 receptor $\alpha$; IL-15 transpresentation; Dendritic cell-vaccination; NK cells; T cells

\section{Introduction}

Already more than four decades ago, dendritic cells (DC) were described as the main orchestrators of the immune system [1]. More specifically, DC can process and present tumor antigens to cytotoxic $\mathrm{T}$ lymphocytes (CTLs), in order to eliminate tumors cells. Due to their capacity to induce antigen-specific CTL responses, DC-based vaccines were introduced in clinical trials to treat cancer patients, exactly two decades ago $[2,3]$. Since then, numerous clinical studies to test the feasibility and efficacy of DC-based cancer vaccines have been performed. In the majority of studies, DC vaccines have been shown to be safe and well tolerated. Moreover, there is a growing body of evidence that DC-based vaccination can be of clinical benefit to cancer patients $[2,4,5]$. Tumor types with improved survival results following DC vaccination include melanoma, prostate cancer, malignant glioma, renal cell cancer and lung cancer $[2,6]$. Although these results encourage to continue with antitumor DC vaccination, there is room for improvement to enhance the potency and efficacy of the currently used DC vaccine preparations alone or as part of a combination strategy to further increase the overall survival and the number of responding cancer patients [7-9].

To date, the DC vaccine manufacturing protocol which is most often used in clinical trials involves a one-week, two-step protocol $[7,10,11]$. The first step is the differentiation of peripheral blood monocytes into immature DC in the presence of interleukin (IL)-4 and granulocyte macrophage colony-stimulating factor (GM CSF). The second step is carried out in the last two days of the protocol and involves DC maturation in the presence of IL $1 \beta$, IL- 6 , tumor necrosis factor (TNF)- $\alpha$ and prostaglandin $\mathrm{E}_{2}\left(\mathrm{PGE}_{2}\right)$. A growing body of evidence indicates that these 'gold standard' IL-4 DC might be suboptimal for inducing anticancer immunity [7]. In view of this, we and others have designed new protocols for DC vaccine manufacturing, incorporating IL-15 [12-17]. IL-15 has potent stimulatory effects on both the innate and adaptive components of the antitumor immune response $[10,12,18,19]$, and is therefore believed to be one of the most promising molecules for antitumor immunotherapy. This is illustrated by its top position in the US National Cancer Institute's ranking of 20 immunotherapeutic drugs with the greatest potential for broad usage in cancer therapy [20]. In this review, we report how IL-15 and/or the a part of the IL-15 receptor has been implemented into a newly designed DC vaccine to optimize its effects on both the innate as well as the adaptive parts of the immune system. We describe the effects of the IL-15 transpresentation mechanism on DC-mediated activation of NK cells and CTLs. Finally, the potential of this optimized DC vaccine in combinatorial antitumor immunotherapy approaches is discussed.

\section{IL-15 transpresentation and generation of IL-15- transpresenting DC by means of mRNA electroporation}

In contrast to other cytokines, the IL-15 signal is transmitted via a unique mechanism called transpresentation, which contributes to the unique properties of IL-15 [21-23]. This involves the presentation in trans of IL-15 bound to the a moiety of the IL-15 receptor (IL-15Ra) to the $\beta \gamma$ chains of the IL-15 receptor on neighboring cells [24-29]. Both NK cells and CTLs express the IL-15 $\beta \gamma$ receptor and are thus receptive for stimulation by the IL-15/IL-15R $\alpha$ complex [13,30-33]. Different IL-15/IL-15Ra-targeting immunotherapy approaches have been proposed, including free protein and cell-associated strategies.

*Corresponding author: Johan MJ Van den Bergh, Laboratory of Experimental Hematology, Antwerp University Hospital (UZA), Wilrijkstraat 10, B-2650 Edegem, Belgium, Tel: +32 3821 4112; Fax: +32 3821 4456; E-mail: johan.vandenbergh@uantwerpen.be

Received December 14, 2015; Accepted January 21, 2016; Published January 23, 2016

Citation: Van den Bergh JMJ, Lion E, Anguille S, Van Tendeloo FI, Smits ELJM (2016) Interleukin-15 and Interleukin-15 Receptor a mRNA-Engineered Dendritic Cells as Promising Candidates for Dendritic Cell-Based Vaccination in Cancer Immunotherapy. J Cancer Sci Ther 8: 015-019. doi:10.4172/1948-5956.1000381

Copyright: @ 2016 Van den Bergh JMJ, et al. This is an open-access article distributed under the terms of the Creative Commons Attribution License, which permits unrestricted use, distribution, and reproduction in any medium, provided the original author and source are credited. 
Citation: Van den Bergh JMJ, Lion E, Anguille S, Van Tendeloo FI, Smits ELJM (2016) Interleukin-15 and Interleukin-15 Receptor a mRNAengineered Dendritic Cells as Promising Candidates for Dendritic Cell-based Vaccination in Cancer Immunotherapy. J Cancer Sci Ther 8: 015-019. doi:10.4172/1948-5956.1000381

The group of HC Wong developed a fusion protein of a novel IL-15 mutant with enhanced IL-15 biological activity [34] containing the sushi domain of IL-15Ra. This IL-15 superagonist complex, called ALT803 , improved the IL-15 half-life and resulted in increased numbers of activated $\mathrm{CD}^{+} \mathrm{T}$ cells and NK cells [35]. Due to the positive results in preclinical studies and the ability to upscale the production of ALT803, this IL-15/IL-15Ra fusion complex was implemented into clinical trials in patients with multiple myeloma (NCT02099539), bladder cancer (NCT02138734), hematological malignancies (NCT01885897), non-Hodgkin lymphoma (NCT02384954), non-small cell lung cancer (NCT02523469) and advanced melanoma (NCT01946789). All these clinical studies are designed to obtain the optimal dose level and administration scheme of ALT-803. Although very promising in the treatment of different kinds of cancers, ALT-803 is administered systemically in all these studies, which can dramatically augment the probability of adverse side-effects or autoimmunity. To fully benefit from the advantages of IL-15/IL-15R $\alpha$ complexes while bypassing systemic side effects, the use of cell carriers to deliver IL-15/IL-15Ra in a more controlled way might be preferable. It is within this context that the DC-based immunotherapy approaches come to the fore. Using the mRNA electroporation technique (detailed in [36]), we genetically engineered DC to express IL-15 and IL-15Ra. These DC, further called IL-15/IL-15Ra EP DC (Figure 1), were generated according to the one-week, two step DC vaccine manufacturing protocol described above with the following two modifications. First, in our protocol, only TNF- $\alpha$ and PGE 2 were used during DC maturation. Second and most importantly, both IL-15 and IL-15R $\alpha$ were co-transfected by means of mRNA electroporation into the matured IL- 4 DC. We showed that IL-15/IL-15Ra is highly expressed on the cell surface of these IL-15/
IL-15Ra mRNA-electroporated DC [37]. In addition to local delivery of IL-15, these IL-15/IL-15Ra-expressing DC have two important advantages, as compared to non-transient systemic protein delivery, resulting from the mRNA electroporation technique. From a Good Manufacturing Practices (GMP) perspective, it is easier to obtain clinical grade IL-15 mRNA than protein, so mRNA-based transfection (e.g. through electroporation) with IL-15 mRNA in DC circumvents the obstacle of the scarcely available clinical grade protein IL-15. Biologically, a transient effect of IL-15/IL-15Ra complexes is in favor of NK cell activation as compared to prolonged stimulation by IL-15/ IL-15Ra complexes [38]. In conclusion, our IL-15 and IL-15Ra mRNA transfected DC are promising candidates to improve current DC-based vaccination strategies.

\section{IL-15/IL-15Ra effects on NK cells}

In antitumor immunotherapy, DC vaccines are still primarily designed to induce effective adaptive (CTL-mediated) responses, disregarding the antitumor potential of the innate immune system (primarily NK cells). Nevertheless, bidirectional crosstalk between DC and NK cells results in enhanced activation of both cell types and increases their antitumor activity [39-41]. In addition, since NK cells express the $\beta \gamma$-moiety of the IL-15 receptor, it has been acknowledged that IL-15 can be an important mediator in DC-mediated NK-cell activation $[12,23,42,43]$. This has driven us to examine the NK-cell activating properties of our IL-15/IL-15R $\mathrm{EP}$ DC with respect to phenotypical activation, NK cell-mediated killing of tumor cells and production of both proinflammatory and lytic effector cytokines (Figure 2A). To demonstrate the contribution of the IL-15 transpresentation mechanism, the effects of IL-15/IL-15Ra EP DC were compared with
Monocyte
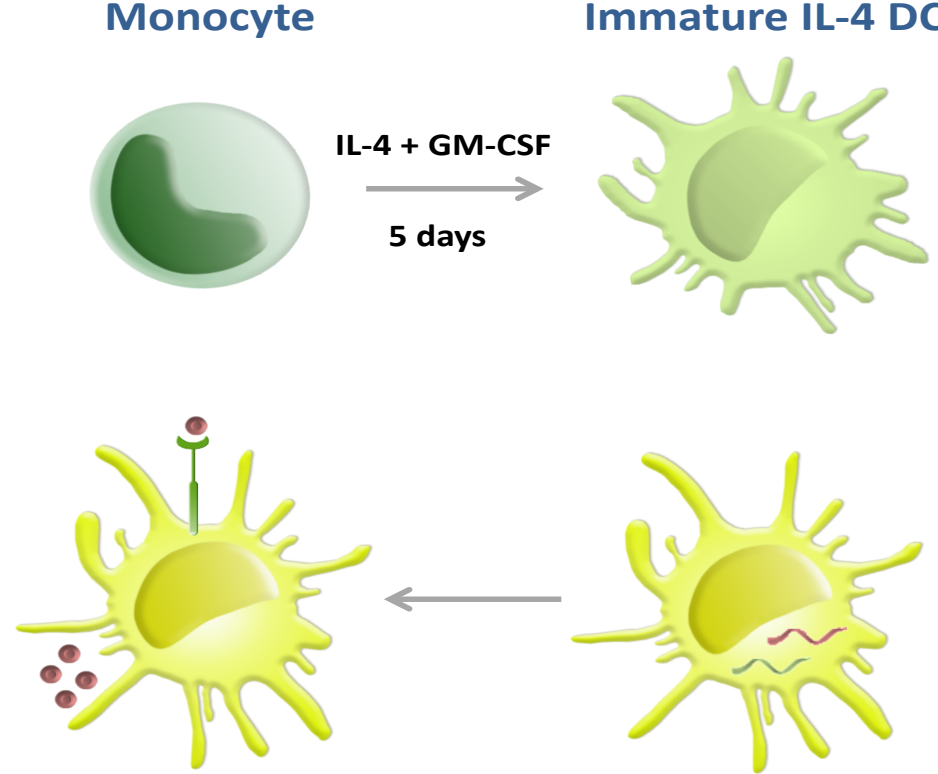

Mature IL-4 DC

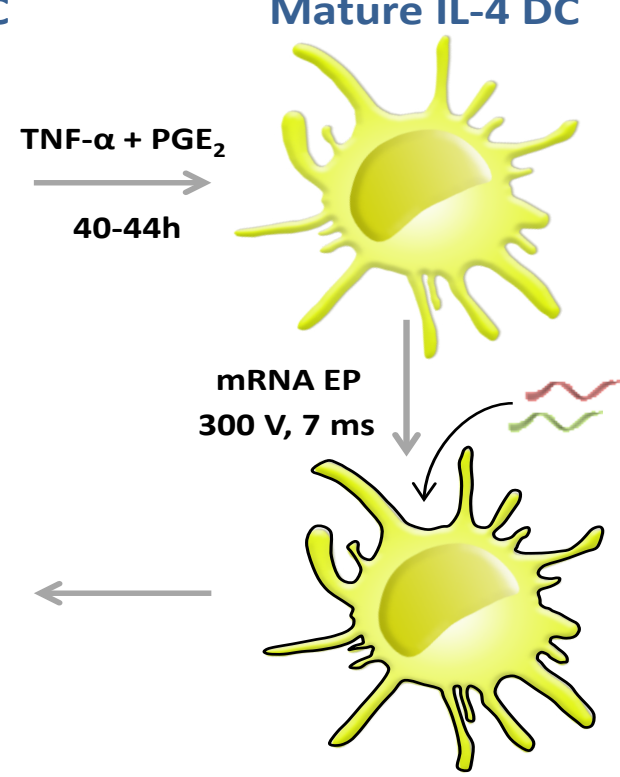

IL-15/IL-15R $\alpha$ EP DC

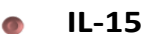

( IL-15R $\alpha$

IL-15 mRNA

IL-15R $\alpha$ mRNA

$E P=$ electroporation

Figure 1: Preparation of monocyte-derived IL 15/IL-15Ra EP DC in a three-step protocol. In the first two steps, monocytes are differentiated in the presence of IL-4 and GM-CSF into immature IL-4 DC, followed by maturation in the presence of TNF- $\alpha$ and PGE . In the third step, IL-15, IL-15R a and/or tumor-specific antigen mRNA are co-electroporated into the matured DC to obtain IL-15/IL-15Ra-producing DC. Abbreviations: DC: Dendritic Cell; EP: Electroporation; GM-CSF: Granulocyte Macrophage Colony-Stimulating Factor; IL: Interleukin; IL-15Ra: Interleukin-15 Receptor alpha; PGE ${ }_{2}$ : Prostaglandin $E_{2}$; TNF- $\alpha$ : Tumor Necrosis Factor Alpha. 
Citation: Van den Bergh JMJ, Lion E, Anguille S, Van Tendeloo FI, Smits ELJM (2016) Interleukin-15 and Interleukin-15 Receptor a mRNAengineered Dendritic Cells as Promising Candidates for Dendritic Cell-based Vaccination in Cancer Immunotherapy. J Cancer Sci Ther 8: 015-019. doi:10.4172/1948-5956.1000381

those of mock transfected DC (Mock EP DC) and DC transfected only with IL-15 but without IL-15Ra (IL-15 EP DC) [37].

In a first series of experiments, IL-15 and/or IL-15Ra-engineered DC were cocultured with autologous NK cells to check for changes in the expression of activation markers and natural cytotoxicity receptors on the NK cells. Although NK cells showed a clear increase of NKp30, NKp44, NKp46, NKG2D, CD69 and CD56 after coculture with IL-15 EP DC, the enhancement was more pronounced when IL-15/IL-15Ra EP DC were used for NK-cell priming. Next, we investigated whether these DC activated NK cells were capable of killing tumor cells, which is pivotal in an antitumor DC therapy setting. In these experiments, DC-primed NK cells were cocultured with both NK cell-sensitive and resistant tumor cells, the latter being Daudi cells (Burkitt's lymphoma cell line). In both cases, IL-15 obtained from either IL-15 EP DC or IL-15/IL-15Ra EP DC resulted in increased NK cell-mediated killing of the tumor cells, with a statistically significant superior effect when IL15 was presented by IL- $15 \mathrm{R} a$ as compared to IL-15 EP DC. The fact that IL-15Ra is desirable for appropriate NK cell-priming by DC [42] and that transcellular IL-15 presentation by IL-15Ra is the key mechanism in the induction of NK cell-mediated killing [43-45], ratify the usefulness of our IL-15/IL-15Ra mRNA-electroporated DC, especially in malignancies that are susceptible to NK cell-mediated killing. From a mechanistic point of view, we found that the increased tumor cell killing was linked to increased granzyme B and perforin secretion by NK cells, indicating that these lytic effector molecules play a principal role in the observed NK cell-mediated killing of tumor cells. In addition, transcellular presentation of IL-15 to NK cells leads to enhanced IFN- $\gamma$ secretion, promoting the differentiation of $\mathrm{T}$ helper 1 cells, which is in favor of generating antitumor immunity $[23,42,43]$. Overall, our data show that IL-15/IL-15Ra EP DC are excellent stimulators of autologous NK cells, in favor of improving current DC vaccination strategies.

\section{IL-15/IL-15Ra effects on CTLs}

As principal effector killer cells of the adaptive immune system, CTLs are still the primary targets of DC-based antitumor vaccinations. Despite more studies show a clear induction of CTL immunity in cancer patients, durable clinical responses after DC vaccination could be improved [2]. Mechanisms that can augment the amount of CTLs, increase their antitumor activity and enhance their in vivo longterm survival are highly favorable in the battle against cancer. IL-15 transpresented by IL-15R $\alpha$ has already been demonstrated to expand tumor-specific CD8 ${ }^{+}$CTLs and to promote their interferon (IFN)- $\gamma$ synthesis and cytotoxicity in a metastatic and autochthonous liver cancer mouse model [46]. Moreover, this IL-15 transpresentation mechanism induced robust IL 12 and IFN- $\gamma$ production, as seen in the plasma of tumor-bearing mice, and reduced the expression of co-inhibitory molecules on DC [46]. According to these results, integrating the IL-15 transpresentation mechanism into a DC vaccine, such as in our IL-15/ IL-15R $\alpha$ EP DC, could be advantageous to induce adaptive immunity (Figure 2B). This has led to the start of a next series of experiments, whereby the potential of the IL-15/IL-15Ra EP DC to increase specific CTL-mediated antitumor responses will be investigated.

Since DC can be loaded with different kinds of tumor antigens and since the expansion and survival effects of IL-15 on CTLs are antigenindependent [47], our DC vaccine can be used against a broad range of tumor types. Our preferred antigen-loading strategy is mRNA electroporation for different reasons. First, mRNA transfection results in a superior cytoplasmic expression efficiency, is easier to execute as
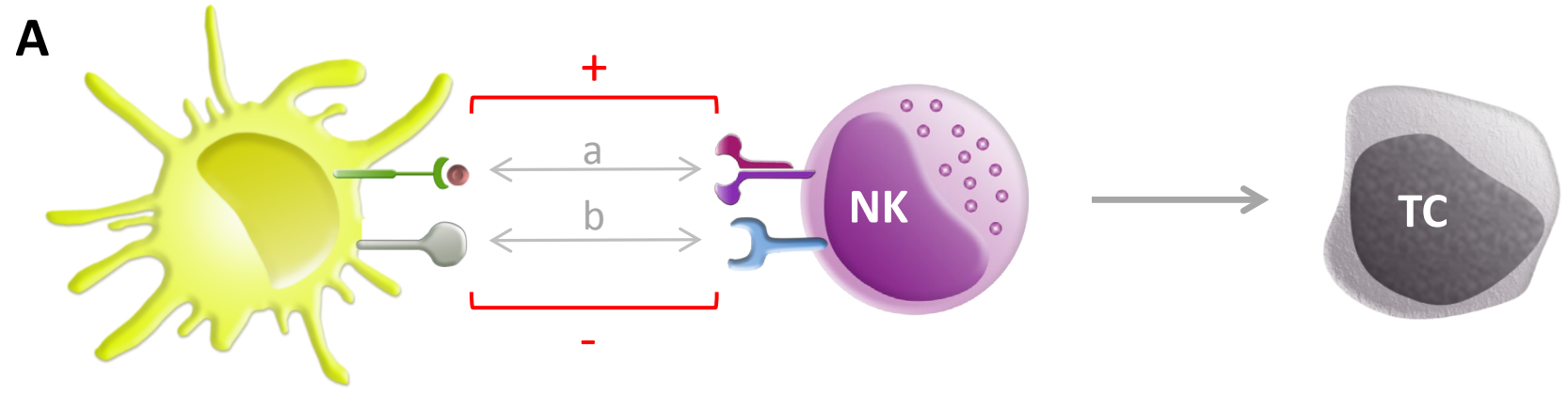

B
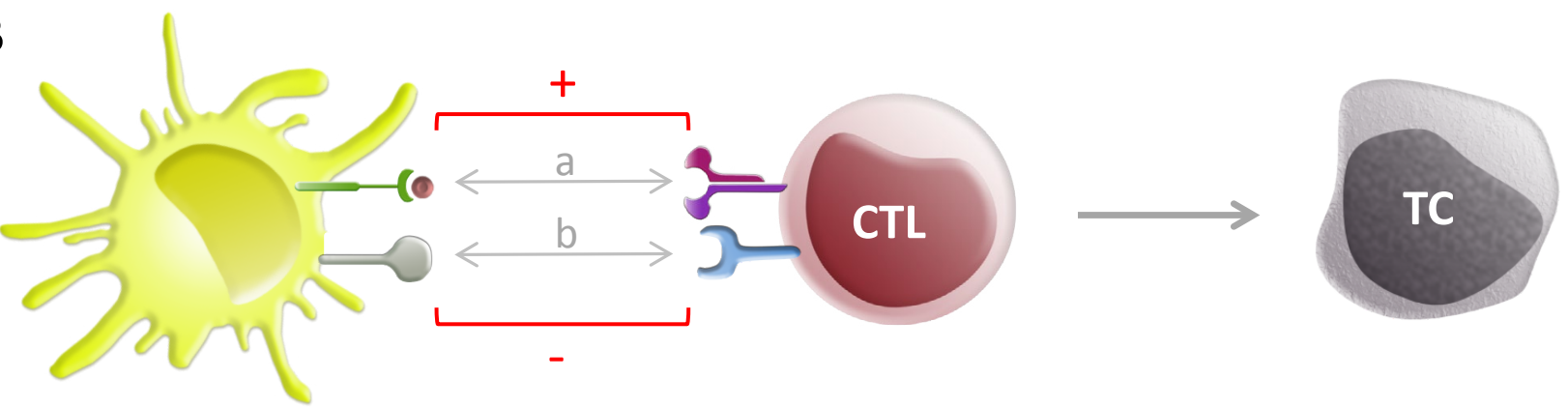

Figure 2: IL-15/IL-15R $\alpha$ EP DC can activate both NK cells (A) and CTL (B) in order to eliminate tumor cells. The interaction between IL-15/IL-15Ra-complexes and IL-15Rßy-expressing cells can further activate the latter (a). Interaction between the immune checkpoint receptor PD-1 and its ligand PD-L1 has an inhibitory effect on the activation of CTLs and NK cells (b). Abbreviations: CTL: Cytotoxic T Lymphocytes; IL-15: Interleukin-15; IL-15Ra: Interleukin-15 Receptor Alpha; NK: Natural Killer Cell; PD-1: Programmed Cell Death Protein 1 Receptor; PD-L1: Programmed Death-Ligand 1; TC: Tumor Cell. 
Citation: Van den Bergh JMJ, Lion E, Anguille S, Van Tendeloo FI, Smits ELJM (2016) Interleukin-15 and Interleukin-15 Receptor a mRNAengineered Dendritic Cells as Promising Candidates for Dendritic Cell-based Vaccination in Cancer Immunotherapy. J Cancer Sci Ther 8: 015-019. doi:10.4172/1948-5956.1000381

compared to viral transduction protocols and has a beneficial clinical safety profile (due to a strictly transient expression and inability to integrate into the host genome) [48]. Secondly, mRNA electroporation results in the presentation of multiple $\mathrm{T}$ cell epitopes without the need for prior knowledge of the patient's HLA type. Lastly, tumor antigen mRNA can be co-electroporated simultaneously with other translational mRNAs coding for immune-stimulating proteins, avoiding additional manipulations. Due to the clear CTL-activating effect of IL-15/IL-15Ra complexes, in addition to activation of NK cells, IL-15/IL-15Ra EP DC are strong candidates for the improvement of current $\mathrm{DC}$ vaccination strategies.

\section{Conclusions and Future Perspectives}

Although DC vaccination can result in a survival advantage of cancer patients, there is a general agreement among cancer researchers that the true clinical benefit of DC based cancer immunotherapy has not been attained yet [10]. In order to improve the clinical outcome of DC based immunotherapies, an improvement of the current DC vaccine preparations is urgently required. Together with the launch of DC vaccination, IL-15 was discovered and identified as a stimulus of both innate and adaptive antitumor immune effector cells. To date, IL-15 has become one of the most promising molecules for antitumor immunotherapy illustrated by its top position in the US National Cancer Institute's ranking of 20 immunotherapeutic drugs with the greatest potential for broad usage in cancer therapy [20]. IL-15 owes this nomination partly to its unique transpresentation mechanism, whereby IL-15Ra transpresents IL-15 to neighboring cells. We believe there is a momentum to integrate this superior IL-15 transpresentation mechanism in current DC vaccines. This integration has already led to an acknowledged increased activation of autologous NK cells in vitro, including enhanced NK cell-mediated killing of otherwise NK cellresistant tumor cells. On top, IL-15/IL-15R $\alpha$ EP DC has the potential to improve activation of antigen-specific antitumor $\mathrm{T}$ cells, which is favorable in the combat against cancer.

However, the tumor immunosuppressive environment could impede the powerful effects of our IL-15/IL-15R $\alpha$ EP DC. To overcome this hurdle, we suggest to combine our immunostimulatory DC vaccine with strategies which counteract the mechanisms used by tumors to evade immune control, such as B7/cytotoxic T lymphocyte associated protein 4 (CTLA-4) and programmed death ligand 1 (PD-L1)/ programmed cell death protein 1 (PD-1) interactions [22,23]. In recent years, the use of PD-L1, PD-1 and CTLA-4 blocking antibodies gained momentum, which already led to FDA approval of ipilimumab (antiCTLA-4), pembrolizumab (anti-PD-1) and nivolumab (anti-PD-1) for the treatment of advanced melanoma and lung cancer patients [4951]. As an alternative, the use of silencing RNAs (siRNAs) to block PD-L1 and PD-L2, expressed on DC, has been suggested [52,53]. In this context, the immunostimulatory capacity of DC can be boosted further, which might be beneficial for the antitumor effects of our IL15/IL-15Ra EP DC. Altogether, the use of IL-15/IL-15Ra EP DC is an appealing strategy in the optimization of current DC-based vaccination strategies.

\section{Acknowledgments}

This work is supported by the research grant STK2012-193 of the Belgian Stichting tegen Kanker and the Methusalem program of the Flemish Government on the name of $\mathrm{H}$. Goossens. J. Van den Bergh receives a fellowship from the Faculty of Medicine and Health Sciences of the University of Antwerp. The authors like to thank B. Van den Bergh for his contribution to Figures 1 and 2.

\section{References}

1. Steinman RM, Cohn ZA (2007) Pillars Article: Identification of a novel cell type in peripheral lymphoid organs of mice. I. Morphology, quantitation, tissue distribution. J. Exp. Med.1973 137: 1142-1162. J Immunol 178: 5-25.

2. Anguille S, Smits EL, Lion E, van Tendeloo VF, Berneman ZN (2014) Clinical use of dendritic cells for cancer therapy. Lancet Oncol 15: e257-267.

3. Hsu FJ, Benike C, Fagnoni F, Liles TM, Czerwinski D, et al. (1996) Vaccination of patients with B-cell lymphoma using autologous antigen-pulsed dendritic cells. Nat Med 2: 52-58.

4. Draube A, Klein-González N, Mattheus S, Brillant C, Hellmich M, et al. (2011) Dendritic cell based tumor vaccination in prostate and renal cell cancer: a systematic review and meta-analysis. PLoS One 6: e18801.

5. Mantia-Smaldone GM, Chu CS (2013) A review of dendritic cell therapy for cancer: progress and challenges. BioDrugs 27: 453-468.

6. Takahashi H, Okamoto M, Shimodaira S, Tsujitani S, Nagaya M, et al. (2013) Impact of dendritic cell vaccines pulsed with Wilms' tumour-1 peptide antigen on the survival of patients with advanced non-small cell lung cancers. Eur $\mathrm{J}$ Cancer 49: 852-859.

7. Anguille S, Lion E, Van den Bergh J, Van Acker HH, Willemen Y, et al. (2013) Interleukin-15 dendritic cells as vaccine candidates for cancer immunotherapy. Hum Vaccin Immunother 9: 1956-1961.

8. Bot A, Marincola F, Smith KA (2013) Repositioning therapeutic cancer vaccines in the dawning era of potent immune interventions. Expert Rev Vaccines 12: 1219-1234.

9. Datta J, Terhune JH, Lowenfeld L, Cintolo JA, Xu S, et al. (2014) Optimizing dendritic cell-based approaches for cancer immunotherapy. Yale J Biol Med 87: 491-518

10. Anguille S, Smits EL, Bryant C, Van Acker HH, Goossens H, et al. (2015) Dendritic Cells as Pharmacological Tools for Cancer Immunotherapy. Pharmacol Rev 67: 731-753.

11. Tuyaerts S, Aerts JL, Corthals J, Neyns B, Heirman C, et al. (2007) Current approaches in dendritic cell generation and future implications for cancer immunotherapy. Cancer Immunol Immunother 56: 1513-1537.

12. Anguille S, Van Acker HH, Van den Bergh J, Willemen $\mathrm{Y}$, Goossens $\mathrm{H}$, et al. (2015) Interleukin-15 Dendritic Cells Harness NK Cell Cytotoxic Effector Function in a Contact- and IL-15-Dependent Manner. PLoS One 10: e0123340.

13. Burkett PR, Koka R, Chien M, Chai S, Boone DL, et al. (2004) Coordinate expression and trans presentation of interleukin (IL)-15Ralpha and IL-15 supports natural killer cell and memory CD8+ T cell homeostasis. J Exp Med 200: 825-834.

14. Harris KM (2011) Monocytes differentiated with GM-CSF and IL-15 initiate Th17 and Th1 responses that are contact-dependent and mediated by IL-15. J Leukoc Biol 90: 727-734.

15. Hira SK, Mondal I, Manna PP (2015) Combined immunotherapy with whole tumor lysate-pulsed interleukin-15-activated dendritic cells and cucurbitacin I promotes strong CD8(+) T-cell responses and cures highly aggressive lymphoma. Cytotherapy 17: 647-664.

16. Van den Bergh JM, Guerti K, Willemen Y, Lion E, Cools N, et al. (2014) HPV vaccine stimulates cytotoxic activity of killer dendritic cells and natural killer cells against HPV-positive tumour cells. J Cell Mol Med 18: 1372-1380.

17. Zhao Y, Cheng K, Wu Y, Peng XC, Chen Y, et al. (2011) Interleukin-15 enhances T-cell responses by stimulation with dendritic cells. Clin Transl Oncol 13: $275-280$

18. Conlon KC, Lugli E, Welles HC, Rosenberg SA, Fojo AT, et al. (2015) Redistribution, hyperproliferation, activation of natural killer cells and CD8 T cells, and cytokine production during first-in-human clinical trial of recombinant human interleukin-15 in patients with cancer. J Clin Oncol 33: 74-82.

19. Tosic V, Thomas DL, Kranz DM, Liu J, McFadden G, et al. (2014) Myxoma virus expressing a fusion protein of interleukin-15 (IL15) and IL15 receptor alpha has enhanced antitumor activity. PLoS One 9: e109801.

20. Cheever MA (2008) Twelve immunotherapy drugs that could cure cancers Immunol Rev 222: 357-368.

21. Fehniger TA, Cooper MA, Caligiuri MA (2002) Interleukin-2 and interleukin-15 immunotherapy for cancer. Cytokine Growth Factor Rev 13: 169-183.

22. Jakobisiak M, Golab J, Lasek W (2011) Interleukin 15 as a promising candidate for tumor immunotherapy. Cytokine Growth Factor Rev 22: 99-108. 
Citation: Van den Bergh JMJ, Lion E, Anguille S, Van Tendeloo FI, Smits ELJM (2016) Interleukin-15 and Interleukin-15 Receptor a mRNAengineered Dendritic Cells as Promising Candidates for Dendritic Cell-based Vaccination in Cancer Immunotherapy. J Cancer Sci Ther 8: 015-019. doi:10.4172/1948-5956.1000381

23. Van den Bergh JM, Van Tendeloo VF Smits EL (2015) Interleukin-15: new kid on the block for antitumor combination therapy. Cytokine Growth Factor Rev 26: $15-24$.

24. Castillo EF, Schluns KS (2012) Regulating the immune system via IL-15 transpresentation. Cytokine 59: 479-490.

25. Dubois S, Mariner J, Waldmann TA, Tagaya Y (2002) IL-15Ralpha recycles and presents IL-15 In trans to neighboring cells. Immunity 17: 537-547.

26. Müller JR, Waldmann TA, Kruhlak MJ, Dubois S (2012) Paracrine and transpresentation functions of IL-15 are mediated by diverse splice versions of IL-15Ra in human monocytes and dendritic cells. J Biol Chem 287: 4032840338.

27. Sandau MM, Schluns KS, Lefrancois L, Jameson SC (2004) Cutting edge: transpresentation of $\mathrm{IL}-15$ by bone marrow-derived cells necessitates expression of IL-15 and IL-15R alpha by the same cells. J Immunol 173: 6537 6541.

28. Schluns KS, Stoklasek T, Lefrançois L (2005) The roles of interleukin-15 receptor alpha: trans-presentation, receptor component, or both? Int J Biochem Cell Biol 37: 1567-1571.

29. Waldmann TA (2013) The biology of IL-15: implications for cancer therapy and the treatment of autoimmune disorders. J Investig Dermatol Symp Proc 16: S28-30

30. Kokaji Al, Hockley DL, Kane KP (2008) IL-15 transpresentation augments $\mathrm{CD} 8+\mathrm{T}$ cell activation and is required for optimal recall responses by central memory CD8+ T cells. J Immunol 180: 4391-4401.

31. Sato N, Patel HJ, Waldmann TA, Tagaya Y (2007) The IL-15/IL-15Ralpha on cell surfaces enables sustained IL-15 activity and contributes to the long survival of CD8 memory T cells. Proc Natl Acad Sci U S A 104: 588-593.

32. Stoklasek TA, Schluns KS, Lefrançois L (2006) Combined IL-15/IL-15Ralpha immunotherapy maximizes IL-15 activity in vivo. J Immunol 177: 6072-6080.

33. Stonier SW, Ma LJ, Castillo EF, Schluns KS (2008) Dendritic cells drive memory CD8 T-cell homeostasis via IL-15 transpresentation. Blood 112: 4546-4554.

34. Zhu X, Marcus WD, Xu W, Lee HI, Han K, et al. (2009) Novel human interleukin-15 agonists. J Immunol 183: 3598-3607.

35. Han KP, Zhu X, Liu B, Jeng E, Kong L, et al. (2011) IL-15:IL-15 receptor alpha superagonist complex: high-level co-expression in recombinant mammalian cells, purification and characterization. Cytokine 56: 804-810.

36. Smits EL, Anguille S, Cools N, Berneman ZN, Van Tendeloo VF (2009) Dendritic cell-based cancer gene therapy. Hum Gene Ther 20: 1106-1118.

37. Van den Bergh JM, Willemen Y, Lion E, Van Acker HH, De Reu H, et al. (2015) Transpresentation of interleukin 15 by IL-15/IL-15Ra mRNA-engineered human dendritic cells boosts antitumoral natural killer cell activity. Onco target 6536 .

38. Elpek KG, Rubinstein MP, Bellemare-Pelletier A, Goldrath AW, Turley S (2010) Mature natural killer cells with phenotypic and functional alterations accumulate upon sustained stimulation with IL-15/IL-15Ralpha complexes. Proc Natl Acad Sci U S A 107: 21647-21652.
39. Lion E, Smits EL, Berneman ZN, Van Tendeloo VF (2012) NK cells: key to success of DC-based cancer vaccines?. Oncologist 17: 1256-1270.

40. van Beek JJ, Wimmers F, Hato SV, de Vries IJ, Sköld AE (2014) Dendritic cell cross talk with innate and innate-like effector cells in antitumor immunity: implications for DC vaccination. Crit Rev Immunol 34: 517-536.

41. Van Elssen CH, Oth T, Germeraad WT, Bos GM, Vanderlocht J (2014) Natura killer cells: the secret weapon in dendritic cell vaccination strategies. Clin Cancer Res 20: 1095-1103.

42. Koka R, Burkett $P$, Chien M, Chai S, Boone DL, et al. (2004) Cutting edge: murine dendritic cells require IL-15R alpha to prime NK cells. J Immunol 173 3594-3598.

43. Mortier E, Woo T, Advincula R, Gozalo S, Ma A (2008) IL-15Ralpha chaperones IL-15 to stable dendritic cell membrane complexes that activate NK cells via trans presentation. J Exp Med 205: 1213-1225.

44. Dubois S, Patel HJ, Zhang M, Waldmann TA, Müller JR (2008) Preassociation of IL-15 with IL-15R alpha-lgG1-Fc enhances its activity on proliferation of NK and CD8+/CD44high T cells and its antitumor action. J Immunol 180: 20992106.

45. Kobayashi H, Dubois S, Sato N, Sabzevari H, Sakai Y, et al. (2005) Role of trans-cellular IL-15 presentation in the activation of NK cell-mediated killing which leads to enhanced tumor immunosurveillance. Blood 105: 721-727.

46. Cheng L, Du X, Wang Z, Ju J, Jia M, et al. (2014) Hyper-IL-15 suppresses metastatic and autochthonous liver cancer by promoting tumour-specific CD8+ T cell responses. J Hepatol 61: 1297-1303.

47. Lu J, Giuntoli RL, Omiya R, Kobayashi H, Kennedy R, et al. (2002) Interleukin 15 promotes antigen-independent in vitro expansion and long-term survival of antitumor cytotoxic T Iymphocytes. Clin Cancer Res 8: 3877-3884.

48. Van Tendeloo VF, Ponsaerts P, Berneman ZN (2007) mRNA-based gene transfer as a tool for gene and cell therapy. Curr Opin Mol Ther 9: 423-431.

49. Barbee MS, Ogunniyi A, Horvat TZ, Dang TO (2015) Current status and future directions of the immune checkpoint inhibitors ipilimumab, pembrolizumab, and nivolumab in oncology. Ann Pharmacother 49: 907-937.

50. Faghfuri E, Faramarzi MA, Nikfar S, Abdollahi M (2015) Nivolumab and pembrolizumab as immune-modulating monoclonal antibodies targeting the PD-1 receptor to treat melanoma. Expert Rev Anticancer Ther 15: 981-993.

51. Marcq E, Pauwels P, van Meerbeeck JP, Smits EL (2015) Targeting immune checkpoints: New opportunity for mesothelioma treatment?. Cancer Treat Rev 41: $914-924$

52. Hobo W, Maas F, Adisty N, de Witte T, Schaap N, et al. (2010) siRNA silencing of PD-L1 and PD-L2 on dendritic cells augments expansion and function of minor histocompatibility antigen-specific CD8+ T cells. Blood 116: 4501-4511.

53. Hobo W, Novobrantseva TI, Fredrix H, Wong J, Milstein S, et al. (2013) Improving dendritic cell vaccine immunogenicity by silencing PD-1 ligands using siRNA-lipid nanoparticles combined with antigen mRNA electroporation. Cancer Immunol Immunother 62: 285-297. 